\title{
The Impact of a Calibration Strategy on Student Self-Efficacy in a Pharmacotherapy Course
}

\section{Suzanne E Hiller ${ }^{1}$, Carolyn Ford ${ }^{2}$ and Angela Pegram ${ }^{3 *}$}

${ }^{1}$ Assistant Professor; Wingate University School of Graduate Education; Wingate, NC, USA

${ }^{2}$ Professor; Wingate University School of Pharmacy; Wingate, NC, USA

${ }^{3}$ Associate Professor; Wingate University School of Pharmacy; Wingate, NC, USA

*Corresponding Author: Angela Pegram, Associate Professor; Wingate University

School of Pharmacy; Wingate, NC, USA.
Received: September 24, 2020

Published: October 16, 2020

(C) All rights are reserved by Suzanne E

Hiller., et al.

\begin{abstract}
Objective: To determine if a self-regulatory calibration strategy for teaching algorithms in a Pharmacotherapy course increases student motivation and achievement in pharmacy programs.

Methods: Second-year students in a Cardiovascular Pharmacotherapy course studying cardiac arrythmias treatment algorithms completed a series of measures to assess motivation and achievement including self-efficacy for pharmacy studies, sense of belonging, and an atrial fibrillation (a fib) case study following a calibration intervention. The purpose of the calibration exercise was to assist students in gauging their performance in correctly using algorithm guidelines.

Results: Fourteen participants completed a set of pre- and post-measures following the intervention. Based on this sample, the results indicated that student self-efficacy for pharmacy studies improved significantly.

Conclusion: This initial study illuminates how the use of calibration techniques supports student learning for difficult topics, such as the application of cardiac arrhythmias treatment algorithms. By providing students with a calibration technique to monitor their understanding of cardiac arrythmias treatment algorithms, students developed stronger self-efficacy for pharmacy studies.
\end{abstract}

Keywords: Calibration Strategy; Student Self-Efficacy; Pharmacotherapy Course

\section{Introduction}

As pharmacists evolve into multifaceted healthcare providers with ever-growing expectations beyond dispensing medications, professionals must exhibit mastery of complex disease processes like cardiovascular disorders. Future pharmacists must be proficient in managing complicated treatment regimens for cardiovascular disease, which remains one of the most prevalent cause of illness today [1].

Of the many cardiovascular disorders, arrhythmias are one of the most difficult concepts for students to grasp. This obstacle is further complicated by clinical treatment guidelines that contain many confusing algorithms [2]. The clinical guidelines for atrial fibrillation (a fib), one of the most common types of arrythmia, is a particularly challenging topic to teach and learn in pharmacy programs. Furthermore, it has been noted that many students tempo- rarily memorize treatment guidelines without fully understanding how to apply the information to patients which becomes problematic as they advance through the pharmacy program [3].

Self-regulation offers a potent method for guiding students in understanding difficult course work; however, this tool is often omitted in classroom instruction [4]. Recent literature reveals that self-regulatory strategies utilized in pharmacy programs support student learning and overall course performance [5]. One such model of self-regulation is known as the Cyclical Self-Regulatory Feedback Loop Model, with the three phases of forethought, performance, and self-reflection [6,7]. In training students to be independent learners, the Cyclical Self-Regulatory Feedback Loop model flows between three cycles: the forethought phase, the performance phase, and the self-reflection phase (See figure 1) [8]. 


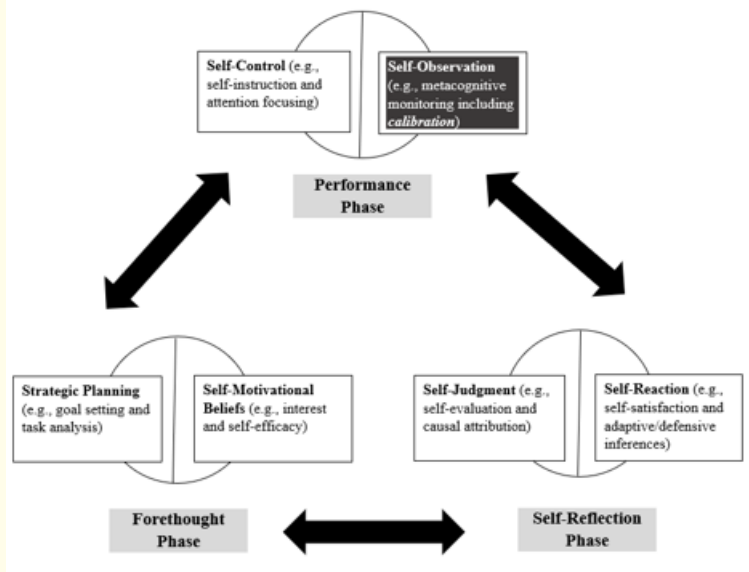

Figure 1: Calibration as part of Zimmerman's cyclical self-regulatory feedback loop model.

For the present study, self-efficacy (developed in the forethought phase) was a key factor. Students with strong self-efficacy or beliefs about their capabilities to complete a task, are better able to focus on calibration or learning strategies [9]. The establishment of strong self-efficacy is critical so that students focus on strategies rather than attributing setbacks on personal deficiencies [10].

The second phase of this model, known as the performance phase and central to the current research study, is when students attempt their pre-selected strategies through self-instruction and metacognitive monitoring. The overarching goal during metacognitive monitoring is to promote awareness of thinking as students attempt tasks based on goal setting and strategy selection [11] through metacognitive prompts or hints to focus students on their thought processes [12].

Calibration is a hallmark of the performance phase wherein individuals compare their performance to standardized criteria. Individuals who do not have accurate calibration often have difficulty making adjustments in the performance phase because they are unaware of potential deficiencies $[4,13]$. Incorporating calibration within instruction and providing feedback and modeling allows students to recognize and make corrections to what they do not know thereby increasing overall achievement [12,14-16].

The third phase is known as the self-reflection phase during which self-regulated learners reflect on their performance via self-judgment and self-satisfaction. Lower performing students tend to have weak calibration, low self-efficacy, and poor adaptive skills in reflecting on their performance $[12,17]$.

As in the case of Zimmerman's model $[6,7]$ training students to apply the treatment algorithm for a fib is an iterative cycle. Figure 2 shows the multi-layered facets of using this type of approach in pharmacy course work. Column 1, the applied skills, depicts the use of an algorithm flowchart as a modified sample [18]. In the center, column 2 shows an instruction framework in which a professor alternates between modeling and asking guiding questions as a form of metacognitive prompts. In addition, the professor models self-instruction and encourages students to use self-talk as they attempt to analyze case scenarios.
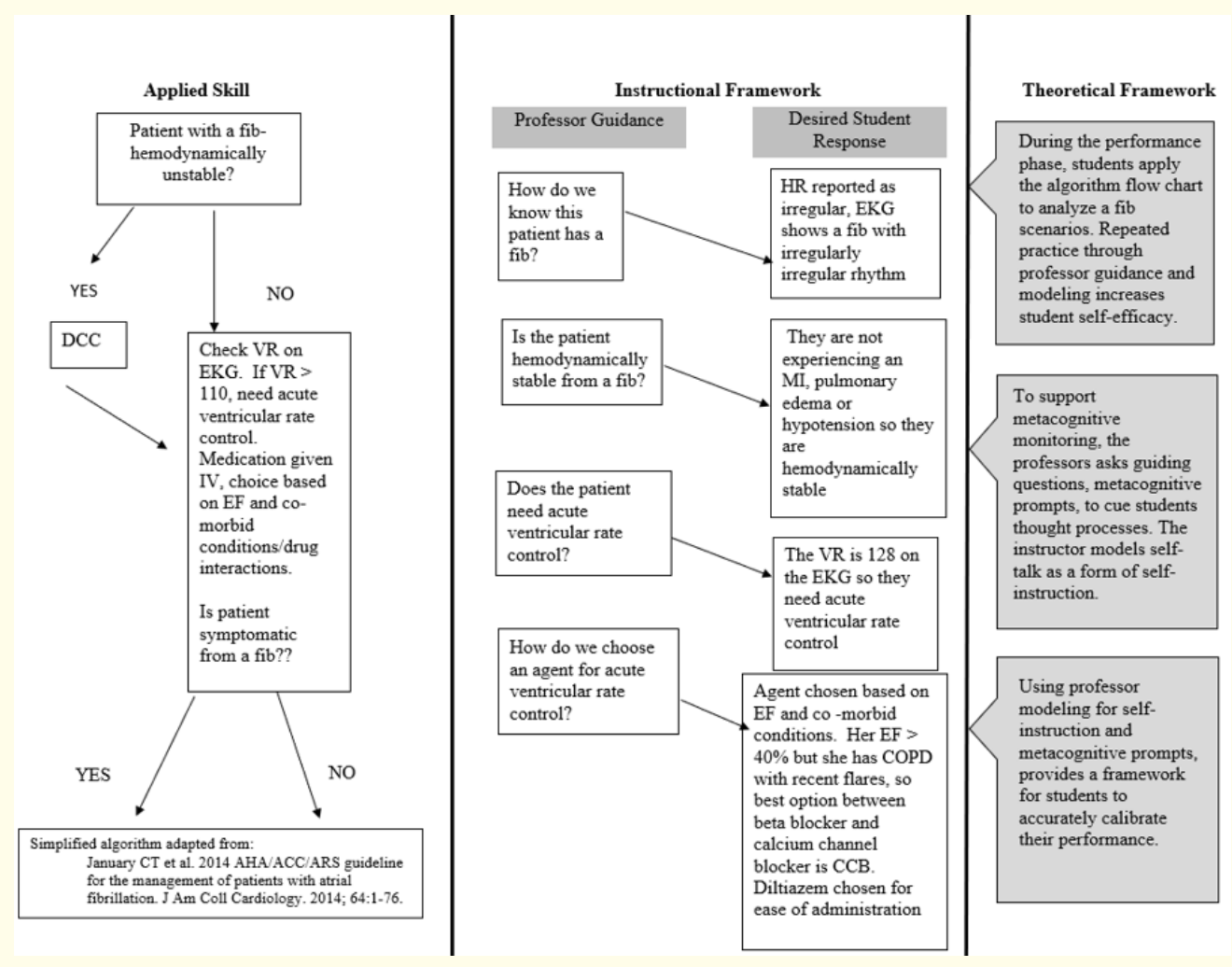

Figure 2: Infusing the performance phase (calibration strategies) in a fib coursework. Applied skills. Based on an algorithm flow chart modified from January., et al [18]. 


\section{Purpose of the Study}

The purpose of the present study was to examine how the integration of calibration strategies within collegiate pharmacy programs influences self-efficacy, sense of belonging and achievement. Based on previous research on calibration strategy use, it was hypothesized that there would be positive gains in self-efficacy, sense of belonging, and achievement following the calibration intervention.

\section{Methods}

Participants and setting

This study occurred in the Fall of 2019 during Cardiovascular Pharmacotherapy (a Year 2 college of pharmacy course) on heart arrythmias in a university in the Southeast region of the United States. Students in the course were invited to participate in a pilot study to assess the impact of calibration strategies on motivational factors (self-efficacy and sense of belonging) and achievement. The average age of the participants was 24.97 years, with $65.5 \%$ female and $29.3 \%$ male. The average GPA was $(n=14, M=$ $3.36, \mathrm{SD}=.33$ ) Fifty-five students completed a battery of scales as a premeasure and for validation purposes. Of these participants, ( $n=14$ ) completed the pre and post measures following the calibration intervention. Training on analyzing treatment algorithms occurred in the classroom with instructor modeling. Participants completed assessments on site prior to and following instruction. The training was approved through institutional research and review board. Both measures were administered through Qualtrics [19] and participants agreed to participate in the study through the online platform.

\section{Intervention}

Arrhythmias are often viewed as one of the hardest and least understood topics in all of the pharmacotherapy modules throughout the pharmacy curriculum. The American Heart Association (AHA) provides clinical guidelines for treatment of a fib [18,20]; however, these guidelines are redundant, confusing and provide several different algorithms for a fib treatment. Consequently, pharmacy students tend to get frustrated and lost in navigating these treatment options. In order to ease the notion that learning the treatment of a fib is "impossible," a simplified treatment algorithm was developed using the current AHA atrial fibrillation guidelines $[19,20]$.

The simplified algorithm has been used with some success over the past 6 years in the Cardiovascular Pharmacotherapy course.
However, students have consistently scored lower on written a fib exam-based cases in comparison to all other cardiovascular disease cases at a rate of $72 \%$ vs $79 \%$ respectively over the past 5 years. In an effort to improve students' understanding about a fib treatment algorithms and their ability to apply the concepts to a patient case, a metacognitive monitoring strategy with embedded hints or clues was introduced in a step-wise approach. The template in figure 3 follows Zimmerman's Cyclical Self-Regulatory Feedback Loop Model $[6,7]$ by incorporating forethought (plan), performance (hint as metacognitive monitoring), and self-reflection (solution) elements.

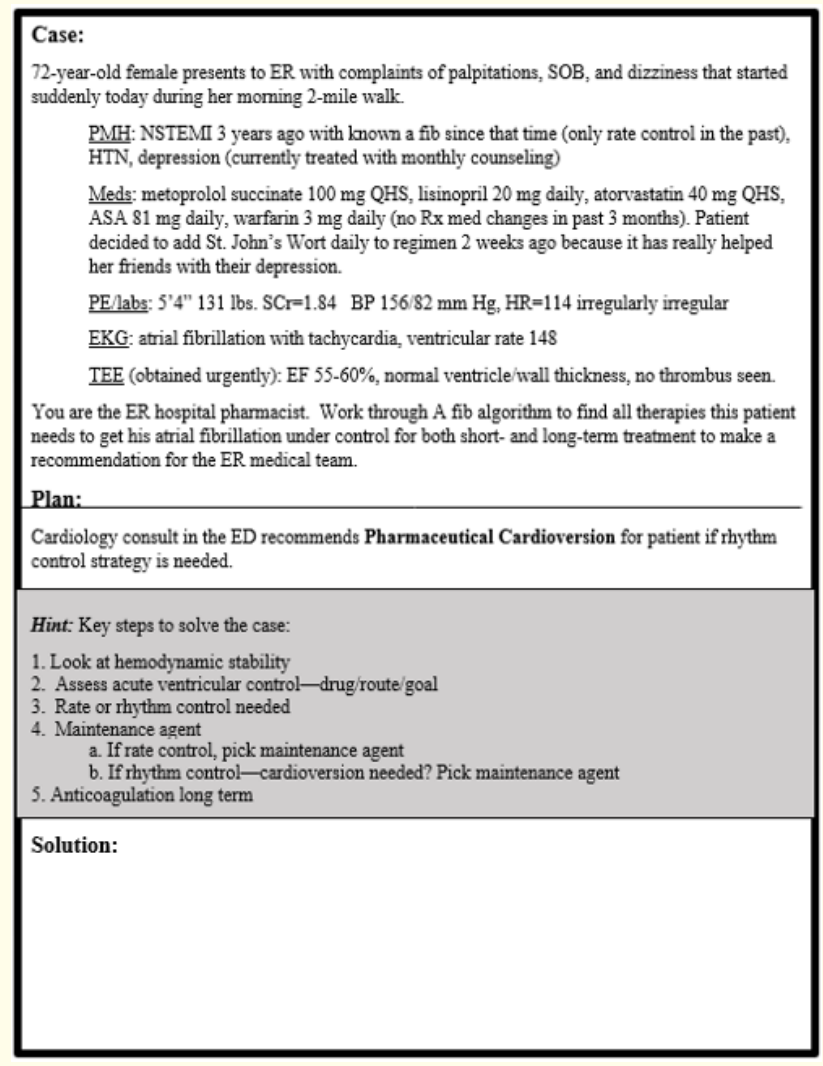

Figure 3: Sample case scenario incorporating Zimmerman's cyclical, self-regulatory feedback loop model $(1988,2013)$.

After didactic instruction and self-practice with written a fib cases, students were given a written a fib patient case to solve during class using both the simplified treatment algorithm and the written steps that included metacognitive hints. Students recorded their answers as they worked through the case. Upon completion of the case, students predicted the number of steps they completed 
correctly which was recorded as a pre-score for the case. As a reflection of calibration, this element in the intervention encouraged students to analyze their performance in solving the case set based on the step-wise approach outlined in the simplified treatment guidelines (See figure 3).

The case was then discussed in detail with the professor leading the class stepwise through the algorithm to solve the case. Teach back was also incorporated during the case session, asking students to remember what to evaluate at each step in the process. Students were also encouraged to use self-talk as a form of selfinstruction (part of the performance phase), such as "How do we know this patient is hemodynamically stable?" or "How do you choose the correct agent for acute ventricular rate control?". Answers to these self-talk questions move the students through the boxes in the algorithm and onto the next step in solving the case. As each step was covered, students graded their written work which was totaled at the end to give a post score for the case. As part of the calibration intervention, students analyzed their performance in solving the case set based on systematized criteria and guidelines (See figure 4).

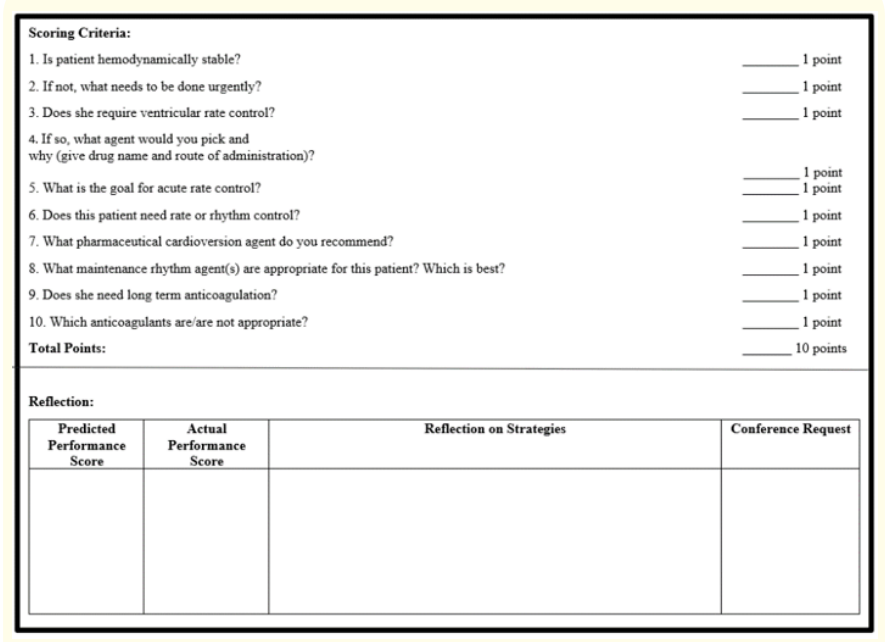

Figure 4: Calibration case score strategy for a fib treatment algorithms.

Approximately 3 weeks after the steps were introduced to the students, a similar written a fib case was given to the students during class time. Students repeated the same steps as before, recording a pre score for the case on their own and then a post score after the case was discussed. Pre and post case scores were collected, just like the first instance the students tried the combined steps/ algorithm approach. Written feedback was also collected to determine if the step approach (in addition to the simplified algorithm) was deemed helpful by the student pharmacists.

\section{Measures}

Demographic survey: To capture the impact of the intervention, demographic information was collected. For the present study, relevant demographic information included age, birthdate, gender, and grade point average (GPA).

Atrial fibrillation (A Fib) case study measure [21]: To assess student achievement within the Pharmacotherapy Course, the A Fib Case Study Measure was scored by a professor for both the pre and post measure. This measure was compiled with a score of 10 points and modeled the format of the intervention as seen in figure 3. Two experts in pharmacotherapy reviewed the measure for content validity.

Self-efficacy for pharmacy studies (Adapted from the engineering self-efficacy scale [22]): The purpose of this measure was to assess students' beliefs in their capabilities for studying pharmacy topics. Participants were asked to rate their confidence in performing certain tasks on a Likert-type scale with 5 indicating "absolutely confident" and 1 "not confident at all". The Engineering Self-Efficacy scale had a Cronbach's alpha of 0.94. For the present study, the scale consisted of six items with a Cronbach's alpha of 0.86 . Sample items included, "identify goals of therapy in the treatment of common cardiovascular disorders," and "utilize critical thinking and concept integration skills to solve therapeutic dilemmas in cardiovascular patient cases".

Psychological sense of school membership for pharmacy students [23]: The purpose of this scale was to examine students sense of belonging within the pharmacy program and was adapted from the original scale by Goodenow. The original scale consisted of 18 items with a Cronbach's alpha reliability coefficient of 0.88 . The adapted scale consisted of eight items with a Cronbach's alpha reliability coefficient of 0.87 . Using a Likert-type scale, students indicated their level of agreement with 5 as "completely true," and 1 as "not true at all." Two items from this scale included, "Other students in my pharmacy program take my opinions seriously," and "I can really be myself in my pharmacy program". 


\section{Results}

Data were analyzed through SPSS 26.0 and assumptions tests for normality with QQ plots, skewness and kurtosis were conducted. Observations followed the guidelines for acceptable skewness $(<2.0)$ and kurtosis $(<7.0)$ for the observations under study to confirm normality [24].

To assess the impact of the calibration intervention on motivation and achievement, table 1 includes descriptive statistics and paired samples $t$-tests for the constructs of self-efficacy for the a fib case study scores, self-efficacy for pharmacy studies, and sense of belonging before and after the calibration intervention. Based on the Cohen's $d$, there was a large main effect for self-efficacy for pharmacy studies following the intervention (4.89). There were minimal effects for the a fib case study score and sense of belonging ( 0.46 and 0.96 respectively).
To address the research question related to the impact of calibration strategies on self-efficacy for pharmacy studies, sense of belonging, and a fib case study scores, paired samples $t$-tests were conducted (See table 1). The findings for the self-efficacy for pharmacy studies, supported the hypothesis in that there were large main effects from pre to post measures for self-efficacy for pharmacy studies $(\mathrm{M}=8.26, \mathrm{SD}=1.53, \mathrm{n}=14 ; \mathrm{M}=19.88, \mathrm{SD}=2.99$, $\mathrm{n}=14$ respectively). These findings indicate that the calibration intervention had a strong influence on student perceptions about their capabilities in pharmacy studies as hypothesized. There were no main effects for sense of belonging $(M=28.90, S D=4.86, n=$ $14 ; \mathrm{M}=28.88, \mathrm{SD}=4.36, \mathrm{n}=14$ respectively) or the a fib case study scores $(\mathrm{M}=8.57, \mathrm{SD}=1.22, \mathrm{n}=14 ; \mathrm{M}=8.21, \mathrm{SD}=1.18, \mathrm{n}=14$ respectively). However, student performance on the atrial fib exam cases improved from 2018 to 2019 (68.8\% compared to 76.5\%) and on the overall course exam (77.4\% and $80.5 \%)$.

\begin{tabular}{|l|c|c|c|c|c|c|c|c|}
\hline \multirow{2}{*}{ Variables } & \multicolumn{3}{|c|}{ Pre } & \multicolumn{3}{|c|}{ Post } & \multirow{2}{*}{ Cohen's d } & \multirow{2}{*}{ T } \\
\cline { 3 - 10 } & N & M & SD & N & M & SD & \\
\hline 1. A fib case study score & 14 & 8.57 & 1.22 & 14 & 8.21 & .30 & 0.40 & 0.46 \\
\hline 2. Self-efficacy for pharmacy studies & 14 & 8.26 & 1.53 & 14 & 9.88 & 2.99 & 4.89 & $0.00^{* *}$ \\
\hline 3. Sense of belonging & 14 & 28.90 & 4.86 & 14 & 28.88 & 4.36 & 0.00 & 0.96 \\
\hline
\end{tabular}

Table 1: Descriptive statistics and paired samples T-tests for A fib case study, self-efficacy for pharmacy studies, and sense of belonging.

$$
\text { Note: }{ }^{*}=\mathrm{p}<.05 \text {, }^{*}=\mathrm{p}<.001 \text {. }
$$

These results revealed that the incorporation of calibration strategies within the course had a strong positive influence on student self-efficacy for pharmacy studies. There was minimal influence on a sense of belonging within the pharmacy program and performance on the a fib case study scores contrary to the hypothesis.

\section{Discussion}

The present study focused on the use of calibration strategies to help students monitor their progress in utilizing a fib treatment algorithm guidelines. The aim of the study was to determine the impact of a calibration study on student self-efficacy for pharmacy studies, sense of belonging, and achievement. Of these factors, selfefficacy for pharmacy studies had strong positive gains following the intervention. This finding is of significance as self-efficacy is a strong predictor of achievement [9]. The calibration strategy had minimal effects on sense of belonging or performance on the a fib content measure. These findings may be indicative that the pro- gression of metacognitive skills requires long term exposure and practice [25]. Perhaps including the calibration strategy over the course of the semester or year may have stronger positive effects on sense of belonging and performance.

\section{Conclusion}

This study provides a glimpse into the potential of infusing calibration strategies within a pharmacy program. The implications of these findings are that the use of calibration strategies is one way to bolster student confidence in pharmacy studies. Future research could center on using the intervention for a longer time frame, including a larger sample size, and comparing motivational, self-regulatory and achievement factors across diverse groups of learners with varying levels of success in pharmacy programs. This study highlights that training pharmacy students to compare their performance to standards and guidelines during instruction is a compelling approach to promoting student self-efficacy for pharmacy work. 


\section{Bibliography}

1. American College of Cardiology. "Coronavirus disease 2019 (COVID-19) provides potent reminder of the risk of infectious agents" (2020).

2. Berg AO., et al. "Clinical practice guidelines in practice and education". Journal of General Internal Medicine 12.2 (1997): S25-S33.

3. Zorek JA., et al. "Bulimic learning". American Journal of Pharmaceutical Education 74.8 (2010): 157.

4. Chen PP and Bonner SM. "A framework for classroom assessment, learning, and self-regulation". Assessment in Education: Principles, Policy, and Practice 3 (2019): 7-19.

5. Voils SA., et al. "Relationship between pharmacy students' use of self-regulated learning strategies and course outcomes". American Journal of Pharmaceutical Education 83.10 (2019): 2216-2221.

6. Zimmerman BJ. "A social cognitive view of self-regulated academic learning". Journal of Educational Psychology 81.3 (1989): 329-339.

7. Zimmerman BJ. "From cognitive modeling to self-regulation: A social cognitive career path". Educational Psychologist 48 (2013): 135-147.

8. DiBenedetto MK and Zimmerman BJ. "Construct and predictive validity of microanalytic measures of students' self-regulation of science learning". Learning and Individual Differences 26 (2013): 30-41.

9. Bandura A. "The exercise of control". New York, NY: W. H. Freeman and Company (1997).

10. Cleary TJ and Labuhn AS. "Application of cyclical self-regulation interventions in science-based contexts". In: Bembenutty H, Cleary TJ, Kitsantas Am eds. Applications of self-regulated learning across Diverse Disciplines. A Tribute to Barry J. Zimmerman. Charlotte, NC: Information Age Publishing, Inc (2013).

11. Veenman MVJ. "Assessing metacognitive deficiencies and effectively instructing metacognitive skills". Teachers College Record 119 (2017): 1-20.

12. Author, 2017.
13. Dunlosky D and Thiede KW. "Four cornerstones of calibration research: Why understanding students' judgments can improve their achievement". Learning and Instruction 24 (2013): 58-61.

14. Bol L., et al. "The effects of individual or group guidelines on the calibration accuracy and achievement of high school biology students". Contemporary Educational Psychology 37 (2013): 280-287.

15. Gutierrez AP and Schraw G. "Effects of strategy training and incentives on students' performance, confidence, and calibration". The Journal of Experimental Education 83.3 (2015): 386404.

16. Labuhn AS., et al. "Enhancing students' self-regulation and mathematics performance: the influence of feedback and selfevaluative standards". Metacognition Learning 5 (2010): 73194.

17. Cleary TJ., et al. "Motivation processes in citizen science programs: Current status and future directions". In: Hiller SE, Kitsantas A, eds. Enhancing STEM motivation through citizen science programs. Hauppauge, NY: Nova Science Publishers, Inc (2019).

18. January CT., et al. "2014 AHA/ACC/HRS Guidelines for the Management of Patients with Atrial Fibrillation". Circulation 130.23 (2014): e199-e267.

19. Qualtrics (2020).

20. January CT., et al. "2019 Focused Update of the 2014 AHA/ ACC/HRS Guidelines for the Management of Patients with Atrial Fibrillation". Circulation 140.2 (2019): e125-e151.

21. Authors, 2020 .

22. Lent RW., et al. "Social cognitive predictors of academic interests and goals in engineering: Utility for women and students at historically black universities". Journal of Counseling Psychology 52.1 (2005): 84-92.

23. Goodenow C. "The psychological sense of school membership among adolescents: scale development and educational correlates". Psychology in the Schools 30.1 (1993): 79-90.

24. Dimitrov DM. "Statistical methods for validation of assessment scale data in counseling and related fields". Alexandria, VA: American Counseling Association (2012). 
25. Van der Stel M and Veenman MVJ. "Metacognitive skills and intellectual ability of young adolescents: A longitudinal study from a developmental perspective". European Journal of Psychological Development 29 (2014): 117-137.

\section{Assets from publication with us}

- Prompt Acknowledgement after receiving the article

- Thorough Double blinded peer review

- Rapid Publication

- Issue of Publication Certificate

- High visibility of your Published work

Website: www.actascientific.com/

Submit Article: www.actascientific.com/submission.php

Email us: editor@actascientific.com

Contact us: +919182824667 